\title{
Body-worn cameras for police accountability: Opportunities and risks
}

\author{
Fanny Coudert ${ }^{a, *}$, Denis Butin ${ }^{b}$, Daniel Le Métayer ${ }^{c}$ \\ a ICRI/CIR, KU Leuven, iMinds, Leuven, Belgium \\ b TU Darmstadt, Germany \\ ' Inria, Université de Lyon, France
}

\section{Keywords:}

Surveillance

Accountability

Police

Cameras

Privacy

Law

Technology

\section{A B S T R A C T}

The use of body-worn cameras by police forces around the world is spreading quickly. The resulting mobile and ubiquitous surveillance is often marketed as an instrument for accountability and an effective way of reducing violence, discrimination or corruption. It also involves remarkable potential for intrusion into the privacy of both individuals and police agents. We analyse the deployment of police body-worn cameras in five countries, investigate their suitability as an accountability tool given the associated privacy threats, and discuss the societal impact of their deployment as well as the risk of function creep.

@ 2015 Fanny Coudert, Denis Butin \& Daniel Le Métayer. Published by Elsevier Ltd. All rights reserved.

\section{Introduction: motivations for the use of police body cameras}

During the summer of 2014, Ferguson (Missouri) was the scene of tragic events. An 18-year-old African American was shot by a police officer, during a routine control, in the middle of the day and outside the reach of video cameras. The police argued that the (six) shots were fired by the police officer in legitimate self-defence as the young man was attacking him. Witnesses related that, on the contrary, the adolescent was standing at a reasonable distance from the police officer, thereby not posing a threat. In such complex and sensitive cases, it is left up to the courts to assess the veracity of the different testimonies, cross-checking other sources of evidence (such as forensic expertise) whenever available. This process is however dependent of highly subjective elements, often giving way to a feeling of injustice among the public, especially minorities, or police officers wrongly accused of misbehaviour. In the Ferguson case, the decision by the Grand Jury not to indict the police officer after reviewing all the evidence sparked another wave of riots fuelled by protesters' outrage. ${ }^{1}$ By contrast, in Mexico, recurrent intent to bribe police officers was evidenced when a woman was filmed threatening the police officer who had arrested her for exceeding the speed limit. ${ }^{2}$

The police are also increasingly faced with recording made by citizens with their smartphones. Some of these videos challenge the accounts provided by police officers, undermining their credibility. As a way of example, in the UK, a few years ago, by-passers recorded the scene when the police shot a presumed criminal, Mark Duggan, during a pre-planned operation. The images showed that at the time of the shooting, Mark

* Corresponding author. Interdisciplinary Center for Law and ICT/Center for Intellectual Property Rights (ICRI/CIR), KU Leuven, iMinds, Sint-Michielsstraat 6, B3443-B3000 Leuven, Belgium. Tel.: +32 16328706.

E-mail address: fanny.coudert@law.kuleuven.be (F. Coudert).

http://dx.doi.org/10.1016/j.clsr.2015.09.002

0267-3649/@ 2015 Fanny Coudert, Denis Butin \& Daniel Le Métayer. Published by Elsevier Ltd. All rights reserved.

${ }^{1}$ Monica Davey and Julie Bosman, 'Protests Flare After Ferguson Police Officer Is not Indicted' (The New York Times, 24 November 2014) $<$ http://www.nytimes.com/2014/11/25/us/ferguson-darren-wilson-shooting-michael-brown-grand-jury.html> [accessed 18 March 2015].

2 Carrie Khan, 'Tijuana Cops Turn On Body Cameras and Hope to Turn Off Bribery' (NPR, 12 March 2015) <http://www .npr.org/sections/parallels/2015/03/12/392553611/with-mixed-feelilngs-tijuana-police-turn-on-the-body-cameras> [accessed 16 June 2015]. 
Duggan was unarmed. The family then accused the police of "executing" him and this sparked violent riots. ${ }^{3}$

In this context, body-worn cameras are increasingly put forward as a solution to control the use of force by the police. In some countries with corruption problems, they are also seen as a way to limit abuse and to restore the credibility of police officers. ${ }^{4}$ Body-worn cameras are wearable video cameras that police officers can wear alongside their badges, clipped to their uniforms or worn as a headset. They fulfil three main interrelated goals. First, they are anticipated to increase the transparency of police behaviour by documenting events, and as such to serve as a reliable source of evidence of interactions between the police and citizens. Then, by exposing bad and good behaviour, it is hoped that they will act as deterrent against the (mis)use of force and discrimination by police officers or violent behaviour of citizens against police. In that sense, several commentators have claimed that the events of Ferguson would not have happened, had the police used wearable cameras. The family of the victim called for police officers to wear body-worn cameras. ${ }^{5}$ Finally, because of this deterrent effect, body-worn cameras are expected to improve policing and restore the trust of communities in their police forces.

Yet, the impact of body-worn cameras on the privacy of both citizens and police officers calls for careful analysis before decision is made for their widespread deployment, particularly in terms of proportionality. Legal and technical considerations will influence the legitimacy of such use.

We start with an overview of the implementation of police body-worn cameras in five countries (the US, the UK, Spain, Belgium and France) and the choices made from technical and legal viewpoints (Section 2). We then turn to analyse the conditions in which such implementation is acceptable (Section 3). Finally, we review the societal impact such widespread deployment might have, especially the risks of function creep and contagion to other fields (Section 4).

\section{Review of the use of police bodycams in five countries}

The deployment of police body-worn cameras has so far mainly taken place in the US and in the UK. Other countries are still testing the technology. In the US, their deployment is driven by discriminatory behaviours from the police and recurrent violent encounters between the police and the citizens. In Europe, while the problem is not that acute in terms of violence,

\footnotetext{
3 'Mark Duggan inquest: Family fury at lawful killing decision' (BBC News, 8 January 2014) <http://www.bbc.com/news/uk-england25657949> [accessed 18 March 2015].

${ }^{4}$ Carrie Khan, 2015, op. cit. fn 5. In a similar line of action, the Bulgarian Interior Minister is planning to equip police cars with GPS, cameras and audio recording systems to combat corruption. 'Bulgaria announces new steps to cut corruption at police roadside checks' (The Sofia Globe, 25 November 2014) <http://sofiaglobe .com/2014/11/25/bulgaria-announces-new-steps-to-cut-corruptionat-police-roadside-checks> [accessed 16 June 2015].

${ }^{5}$ Michael B. Marois, 'Body-Worn Cameras for Police Get Renewed Focus After Ferguson' (Bloomberg, 25 November 2014) <http://www .bloomberg.com/news/articles/2014-11-25/body-worn-cameras-forpolice-get-renewed-focus-after-ferguson> [accessed 18 March 2015].
}

body-worn cameras are seen as a way to restore trust in policing by promoting peaceful interactions between the police and citizens in more sensitive situations or neighbourhoods. Beyond that, in the five countries of study (the US, the UK, Spain, Belgium and France), their deployment seems to operate in a grey zone: while their use would most likely fit under the current legal frameworks, in particular the regulation of video surveillance, some issues (e.g. recording audio or in private dwellings) might form substantial obstacles and need to be dealt with more in detail. This section aims at presenting the different situations factually including contexts, motivations, legal frameworks and available information about the technical solutions. It does not seek to debate the arguments put forward for and against the use of body-worn cameras in each of these countries but rather to provide the raw material for the discussion developed in the rest of the paper.

\subsection{Use of police bodycams in the United States}

In the last few years, police body-worn cameras have gained increased support amongst police officers, the public and the courts. Research conducted by the US Department of Justice showed that 63 agencies had equipped their officers with bodyworn cameras. ${ }^{6}$ US law enforcement agencies are adopting body-worn cameras for a number of purposes: to improve evidence collection, to strengthen officer performance and accountability, to enhance agency transparency, to document encounters between police and the public, and to investigate and resolve complaints and officer-involved incidents. ${ }^{7}$ A recent report from the US Department of Justice mentions the need to "help police departments ensure events are also captured from an officers' perspective" in a "world in which anyone with a cell phone camera can record video footage of a police encounter". ${ }^{8}$ As a way of example, police body-worn cameras were adopted in Rialto (California) to reduce the (mis-)use of force. In New York, their deployment was forced by a court decision in order to provide an objective record of "stop-andfrisks" and assess complaints of racial profiling. ${ }^{9}$ It was further argued that the recordings "would mitigate the impression of individuals that the authorities would be more likely to believe police officers when the only evidence is oral testimony". ${ }^{10}$ The judge also claimed that the use of police body-worn cameras would encourage lawful and respectful interactions on the part of the police and the individual being stopped, by providing overt recording.

As for the technology used, little information is provided. Rialto police forces chose TASER Axon cameras coupled with

\footnotetext{
${ }^{6}$ Ibid.

7 Community Oriented Policing Services (COPS), Implementing a Body-Worn Camera Program, Recommendations and Lessons Learned (2014), p. viii.

${ }^{8}$ Ibid.

${ }^{9}$ Floyd v. City of New York on August 12, 2013, <http://www .nytimes.com/interactive/2013/08/12/nyregion/stop-and-friskdecision.html>.

${ }^{10}$ Timothy Banks, 'Body-worn camera systems: an update' (The Privacy Advisor, 11 November 2014) <https://privacyassociation .org/news/a/body-worn-camera-systems-an-update/> <https:// privacyassociation.org/news/a/body-worn-camera-systems-anupdate/> [accessed 18 March 2015].
} 
EVIDENCE.COM, a cloud-based storage and management system, where video files can be stored and easily accessed for review. ${ }^{11}$

ACLU was the first organisation to produce a white paper which provided clear guidelines to ensure a fair balance between the need to improve police officer's accountability and respect for fundamental rights of both citizens and police officers. These recommendations are discussed at length in Section 3. In 2014, the Community Oriented Policing Services (COPS) of the US Department of Justice published an extensive report providing guidance to law enforcement agencies, based on the first experiences carried out by police departments. The report reviews in detail the implications in terms of privacy, community relationships and internal departmental affairs. It also notes that where the cameras are deployed, they create specific expectations about their use by police amongst courts, arbitrators, civilian review boards and citizens. For instance, people come to expect that officers using body-worn cameras will record video of everything that happens while they are on duty. This thus bears the risk of undermining officers' credibility every time questions arise about an incident that was not captured on video. ${ }^{12}$

The report provides detailed recommendations about when to record, how long the record should be retained, who has access to the footage, who owns the recorded data and how to handle internal, external requests for disclosure and security measures. One important aspect is to ensure the transparency of the policies accompanying the deployment of the devices. Agencies are encouraged to develop their own comprehensive written policy to govern body-worn camera usage. However, it seems that, despite this guidance, police agencies adopting body-worn cameras do not disclose the content of the policies to citizens upon requests. ${ }^{13}$

Another difficulty resides in the conditions surrounding the recordings in private areas. Some states have modified their law to frame the use of police bodycams. The main points of struggle are the audio recording of interactions between the police and the public and recordings within residences (private areas), as all parties involved in an interaction must grant their permission to be recorded. In Pennsylvania, ${ }^{14}$ a new law was enacted which allows police officers to wear body-worn cameras to record their interactions with the public during the course of his/her duties, without prior court approval. Yet, at the time of the recording, the officer must be in uniform or otherwise clearly identified as a law enforcement agent, and must inform

\footnotetext{
11 TASER International, 'City of Rialto Case Study, 2013'<https:// taser-international.cdn.prismic.io/taser-international\%2F8115e245f575-4583-a971-0d00641245fc_rialto_study.pdf> [accessed 18 March 2015].

12 COPS (n 8) fn 10, p. 28.

${ }^{13}$ Jay Stanley, Intervention at the panel on "I spy with my fly when surveillance goes mobile" at Computers, Privacy \& Data Protection (CPDP), 21 January 2015, Brussels, <https://www.youtube.com/ watch?v=DfxP6mGRN-g> [accessed 18 March 2015].

14 'Police may Use Body Cameras to Record Interactions with the Public' (Foreman \& Caraciolo, P.C.) <http://www.theharrisburglawyers .com/2014/02/police-may-use-body-cameras-to-record-interactionswith-the-public/> [accessed 18 March 2015].
}

the individual that they are being recorded. Police officers are not permitted to record within residences.

It is however not always necessary to modify the legal framework. For instance, in California, the Penal Code Section 633 exempts law enforcement officers from having to inform suspects that they are being recorded. Police departments have used general orders to extend this exemption to body-worn cameras. $^{15}$

Finally, it is worth noting that under the Freedom of Information Act, images recorded by police through body-worn cameras are subject to public access. This means that in principle, anyone could freely request and access such images. This has significant implications not only in terms of privacy but also in terms of additional workload for police forces to be able to adequately answer these requests. The press reported that a blanket request for access to body camera footage required the police department addressed to review hundreds of hours of footage in order to blur faces and other sensitive information or to mute the audio. ${ }^{16}$ In order to reduce both the amount of video stored and the requests for access, ACLU suggested that only videos related to incidents involving the use of force, complaints against officers, or possible misconducts should be stored by police department. Only those videos would be subject to public disclosure.

\subsection{Use of police bodycams in the United Kingdom}

The use of body-worn cameras in the UK is quite widespread. According to statistics of the BBC, half of all police agencies have equipped their officers with these devices. ${ }^{17}$

Two recent events have further renewed the interest in these cameras. As mentioned above, the death of Mark Duggan - shot during a planned operation - sparked violent riots when a bypasser disclosed images showing that he was unarmed. Later on, the "Plebgate" scandal renewed the interest in body-worn cameras. A MP was led to resign after having been accused to insult a police officer, accusation that was further proven false by the surveillance camera footage. ${ }^{18}$

In the UK, improving policing and restoring the public's trust by providing an objective account of most controversial confrontations have driven the implementation of body-worn cameras. In that sense, Liberal Democrats unveiled a proposal to force selected groups of police officers to wear

\footnotetext{
${ }^{15}$ Eli Wolfe, 'The unblinking eye-witness: should all police start wearing body cameras?' (California Magazine, Just in, 6 January 2014) <http://alumni.berkeley.edu/california-magazine/just-in/2014-11-24/ unblinking-eyewitness-should-all-police-start-wearing-body> [accessed 18 March 2015].

${ }^{16}$ Bill Lucia, 'Massive public records requests cause police to hit pause on body cam programs' (Cross-cut.com, 10 November 2014), <http://crosscut.com/2014/11/body-cams-washington-seattle-privacydisclosure > [accessed 19 August 2015].

${ }_{17}$ Gary Cutlack, 'Police "body cams" make criminals 90 per cent more likely to confess' (Gizmodo, 21 August 2013) <http://www .gizmodo.co.uk/2013/08/police-body-cams-make-criminals-90-percent-more-likely-to-confess-quickly/> [accessed 18 March 2015].

18 'Plebgate' (Wikipedia) <http://en.wikipedia.org/wiki/Plebgate> [accessed 18 March 2015].
} 
body-worn cameras, namely officers with firearms, members of territorial support groups and in Section 60 stop and search areas. $^{19}$

It is worth noting that the London MET Police is carrying out a large-scale testing. ${ }^{20}$ In September 2014, it was announced that 500 new cameras would be deployed to uniformed fire officers and to members of the Territorial Support Group. During the pilot program, the Mayor's Office for Policing and Crime (MOPAC) and the College of Policing are in charge of assessing their added value in terms of criminal justice outcomes, complaints against police, use of force by the police, amount of time saved in administration tasks and the impact on public trust through the use of cameras. ${ }^{21}$

The MET police will test TASER Axon cameras, which can be attached to sunglasses, a cap, a shirt or head-mounted. As in Rialto, the cloud-based EVIDENCE.COM platform is used together with the cameras. When recording, the cameras capture a wide-angle, full-colour view of what an officer is facing. Specific guidelines have been issued to guide police officers and the decision has been made not to have the cameras permanently switched on. The camera will be turned on when an incident is in progress. Victims (but not suspects) have the right to request the camera to be switched off. In any case, individuals are informed if they are filmed. ${ }^{22}$ The first tests proved to be positive, providing additional evidence towards solving crime or validating an officer's account of events. ${ }^{23}$

The use of police body-worn cameras falls under several pieces of UK legislation such as the Data Protection Act (1998), but also the Protections of Freedoms Act (2012) which installs a Surveillance Camera Code of Practice ${ }^{24}$ and covers any other system for recording or viewing of images for surveillance purposes, including when used by police forces. The code contains twelve guiding principles which should guide police forces when exercising any of their functions, including the decision to deploy body-worn cameras. Compliance of police behaviour with the principles contained in the Code is reviewed by the courts. Police forces need to be able to justify all operational and procedural decisions, from visual/audio capture to ultimate disposal. ${ }^{25}$ A Surveillance Camera Commissioner has been created in order to supervise the integrity of the entire process.

One of the principles of the Code refers to the necessity to specify the purpose for which the surveillance camera system will be used and to justify the need to use such cameras. For

\footnotetext{
19 'Put body cameras on stop and search police, say Lib Dems: Party want laws tightened in effort to increase trust in officers' (Daily Mail Online, 12 August 2014) <http://www.dailymail.co.uk/news/article2722482/Put-body-cameras-stop-search-police-say-LibDems.html> [accessed 18 March 2015].

${ }^{20}$ TASER International, 'London Met Police Extending AXON BodyWorn Camera Pilot to Front Line Officers' (Yahoo! Finance, 30 September 2014) <http://finance.yahoo.com/news/london-metpolice-extending-axon-113000689.html $>$ [accessed 18 March 2015]. ${ }^{21}$ Ibid.

22 'Metropolitan Police officers start wearing body cameras' (BBC News, 8 May 2014) <http://www.bbc.com/news/uk-england-london27313500> [accessed 18 March 2015].

${ }^{23}$ TASER International (n21) op. cit.

${ }^{24}$ Home Office, Surveillance Camera Code of Practice, June 2013.

${ }^{25}$ College of Policing, Body-Worn Video, 2014.
}

example, if the cameras are used for enforcement purposes and to protect the safety of staff and the public, then the ICO (the UK Data Protection Commissioner) advises local authorities to provide officers with clear guidance on when to use the camera and how they should make filmed individuals aware that it is taking place. ${ }^{26}$

Body-worn cameras can also be used when both legitimate and necessary to meet an identified pressing need (proportionality). The ICO called for a strict application of the proportionality test before any decision is made to use police body-worn cameras. It recommends that councils reflect about the use of body-worn cameras or consider whether there was a pressing need to capture images of people in this way, as "filming everyday life via such a system would be unjustified if there was no need". ${ }^{27}$

Other principles mandate to take into account the effect of the cameras on individuals and their privacy, to review regularly whether their use remains justified, or to implement appropriate transparency and accountability mechanisms. The CCTV code of practice ${ }^{28}$ gives more specific advice on when a privacy impact assessment should be carried out.

Other applicable laws are also worth mentioning. The Criminal Procedure and Investigations Act (1996) introduces statutory tests for disclosing material to the defence in criminal cases. These tests entail specific retention obligations for the police, and an obligation to implement a full audit trail, from the point of capture of the image throughout the whole management process. The Regulation of Investigatory Powers Act (2000) will apply when body-worn cameras are used covertly. The Police and Criminal Evidence Act (1984) defines the circumstances under which a person may be photographed by a constable elsewhere than at a police station. It excludes the use of sound recording. If any material from body-worn cameras is to be used to assist with identifying suspects, users must follow the provisions of the Act.

Finally, it is worth noting that, as in the US, the Freedom of Information Act (2000) allows public disclosure of the images recorded by police body-worn cameras. This Act grants general right of access to all types of recorded information held by public authorities, which include the digital images recorded by bodyworn cameras. The Act also provides for a series of exemptions based on the harm that would arise or would be likely to arise from disclosure (for example if disclosure would be likely to prejudice a criminal investigation) or if the release of the information would be contrary to the Data Protection Act. ${ }^{29}$

\footnotetext{
26 'Police, Justice and Borders' (Information Commissioner's Office), $<$ https://ico.org.uk/for-organisations/police-justice/> [accessed 18 March 2015].

${ }^{27}$ Ibid.

${ }^{28}$ Information Commissioner's Office, 'In the picture: A data protection code of practice for surveillance cameras and personal information', 15 October 2014. <http://ico.org.uk/for_organisations/ sector_guides/ /media/documents/library/Data_Protection/ Detailed_specialist_guides/ICO_CCTVFINAL_2301.pdf> [accessed 18 March 2015].

${ }^{29}$ Information Commissioner's Office, The Guide to Freedom of Information, version 4.3, October 2014, p. 29 <https://ico.org.uk/ media/for-organisations/documents/1642/guide_to_freedom_of _information.pdf> [accessed 19 August 2015].
} 
These exemptions limit in practice the cases where the footage would be disclosed.

\subsection{Use of police bodycams in Spain}

The Madrid police force is testing five body-worn cameras. ${ }^{30}$ The stated purpose of the cameras is to protect police officers against attacks or insults from citizens and to assess to what extent the response of police has been proportionate. Recordings will also support the training of police officers. Citizens will be granted access to the recordings that could be used as evidence against an excessive use of force. Initially, bodyworn camera will only be allowed in risky operations, which are however defined broadly as they include patrols in bar areas.

The five cameras will be tested in different cases. Madrid is using the same model as the London MET Police (TASER Axon Body). The cameras used can record up to twelve hours in a row (including audio), even in low-light conditions. Recording is activated by the police officer, but the camera constantly records sequences of 30 seconds (deleted after one minute if the recording is not activated) to register unwarranted attacks. The camera also incorporates a sensor that will send an alarm to central services in case the police officer lays on the ground for more than 40 seconds. It incorporates a GPS. The camera has an angle of 130 degrees to provide a wide view.

The images are sent to a central station via the Internet. They are stored for seven days after which they are permanently deleted if not required by a judge or within a criminal investigation. Recordings are associated with the involved police officer and are accessible only by a limited number of operators from the server.

The use of police body-worn cameras falls under the provisions of both the Spanish Data Protection Act and the Act on Video surveillance. This Act allows the police to use video surveillance cameras in public places (i.e. any place without restrictions of access: streets, parks but also malls, bars, etc.), provided that individuals are previously informed about the recording. To comply with this requirement, cameras will be equipped with a yellow label warning that audio and images are being recorded. Their use in homes or private places is subject to warrant or the prior authorisation of the owner. Images can only be stored for a maximum period of one month, but the Madrid police opted for a period of one week.

\subsection{Use of police bodycams in Belgium}

In Belgium, the death of a citizen who was threatening police officers with a cold steel weapon led the police to test bodyworn cameras in one city (Mechelen). ${ }^{31}$ Police trade unions are however divided about the usefulness of such devices. While some of them see body-worn cameras as useful for deterrent

\footnotetext{
${ }^{30}$ Juan Antonio Pascual, 'Policía de Madrid llevará cámaras en el hombro. 'Es legal?' (Computer Hoy, 16 July 2014) <http://computerhoy .com/noticias/imagen-sonido/policia-madrid-llevara-camarashombro-es-legal-15825>.

31 'Equiper les policiers d'une caméra? Un projet de loi est en cours' (RTBF Info, 30 May 2013) <http://www.rtbf.be/info/belgique/detail _equiper-les-policiers-d-une-camera-un-projet-de-loi-est-encours?id=8006721> [accessed 27 May 2015].
}

purposes, for identification purposes or for documenting events, others argue that their added value is limited as the recording is partial: they record only the reaction of the police officer to the event, not the initial violent act of the perpetrator. Others feel the use of body-worn cameras as a lack of trust in police officers. ${ }^{32}$ Despite these objections, police body-worn cameras were tested in 2013. The camera could be turned on and off by the police officers, left to their appreciation.

Further deployment of body-worn cameras in Belgium is however subject to the modification of the Act on video surveillance, ${ }^{33}$ which strictly regulates the use of mobile cameras for purposes of preventing, documenting, detecting crimes, nuisances, and ensuring public safety. Police forces are allowed to use mobile cameras only to ensure public safety in large gatherings that take place in public spaces (such as streets) or semipublic spaces (such as music festivals or soccer stadiums). The use of mobile cameras should be temporary (i.e. linked to the performance of a specific task) and decided by the police officers in charge. Any other use of mobile cameras will fall under the scope of the Data Protection Act.

The use of police body-worn cameras outside these cases (e.g. during day-to-day operational missions) would qualify as unlawful covert surveillance and as such could be punished by fines or prison sentences. In addition, the resulting evidence would not be deemed admissible as it would have been obtained by a conscious unlawful act by the chief of police services.

Additional barriers stem from other pieces of legislation. The Police Act should be modified to allow the recorded images to be used by police officers as evidence in cases of complaints of citizens against police behaviour (and not only in a judicial procedure). ${ }^{34}$ Modification of the Eavesdropping Act is also necessary as, in its current wording, the consent of all parties to a communication is required for the recording of a private conversation..$^{35}$

In order to remedy this situation, the Belgian legislator has put forward a legislative proposal. The modifications intended to allow police officers to use mobile cameras for the performance of their tasks (to be further specified in a royal decree), in dangerous situations or when the police officer feels threatened for the time necessary to the intervention (decision to be taken by the police officer in open spaces and by the mayor in "semi-public" places, i.e. any building or closed space open to the public for the provision of services ${ }^{36}$ ). The government initially wanted to limit their use to cases where force was allowed. ${ }^{37}$ This provision was however deleted after the Belgian Data Protection Authority considered the wording

\footnotetext{
32 'Homme abattu dans les Marolles: le SLFP pas favorable aux bodycams' (RTBF.BE, 26 May 2013) <http://www.rtbf.be/info/societe/ detail_homme-abattu-dans-les-marolles-le-slfp-pas-favorable-auxbodycams?id=8003704> [accessed 27 May 2015].

${ }^{33}$ Loi réglant l'installation et l'utilisation de caméras de surveillance, 21 March 2007, MB 31 May 2007.

${ }^{34}$ Belgian Privacy Commission, Opinion 42/2013 of 2 October 2013. 35 Ibid.

${ }^{36}$ Article $2.2^{\circ}$ of the Video Surveillance Act.

37 'Equiper les policiers d'une caméra? Un projet de loi est en cours' (RTBF Info, 30 May 2013) <http://www.rtbf.be/info/belgique/ detail_equiper-les-policiers-d-une-camera-un-projet-de-loi-esten-cours?id=8006721> [accessed 27 May 2015].
} 
as too vague. The law proposal also foresees to extend the use of body-worn cameras to other bodies such as civil protection, firefighters, and customs. The text is still under the scrutiny of the Parliament.

\subsection{Use of police bodycams in France}

In France, the introduction of body-worn cameras is justified by the need to document interactions with the public in response to the increased number of videos taken by citizens with their smartphones. It is expected to provide evidence of police's good behaviour ${ }^{38}$ by establishing the truth (determining the facts) and by showing that the use of force was legitimate (establishing the context of police action, documenting behaviour of people in stop-and-frisks). ${ }^{39}$ Their use ultimately strives to pacify relationships between police officers and citizens, relying on the deterrent effect of the camera.

After one year of trials, in 2014, the government asked the company Exavision to deliver 4500 body-worn cameras to police in the next five years. ${ }^{40}$ Some units have however decided to use another brand, GoPro, cameras used for extreme sports, more reliable and with a wider angle of vision.

Press releases report that after showing some reluctance, police officers are welcoming body-worn cameras. Priority will be given to police units located in sensitive areas. The cameras will be used for the mission of securing public order, during day-to-day operations such as identity checks. The cameras are worn with a harness. They offer angles of vision that allow filming a person in its close surroundings and feature six hours of storage. The cameras are constantly recording but the footage is stored only if decided by the police officer. This allows to store the images of the 30 seconds prior to the moment when the officer presses the button, thus giving additional information on the events the camera will keep a record of the previous 30 seconds in order to show tensions that led to justify the officer to make this decision. The cameras are visible on uniforms.

The press has reported that for now, in the context of the testing, six recordings have been passed on to the courts in cases of assaults to police officers. ${ }^{41}$ No report was made of their use in favour of citizens. The images are time-stamped to avoid manipulation, and sealed.

The use of body-worn cameras by police forces falls under the legislation applicable to video surveillance. The use of video surveillance is subject to official authorisation. The authorisation should define the modalities of implementation, such as appointing the person who can consult the recorded images.

\footnotetext{
38 'Le Mans. Les policiers équipés de caméras portables' (Le Maine libre, 6 June 2013) <http://www.lemainelibre.fr/actualite/le-mansles-policiers-equipes-de-cameras-portables-06-06-2013-60152> [accessed 27 May 2015].

${ }^{39}$ Flore Galaud, 'La police de Seine-Saint-Denis s'équipe de minicaméras' (Le Figaro, 3 July 2009) <http://www.lefigaro.fr/actualitefrance/2009/07/03/01016-20090703ARTFIG00333-la-police-de-seinesaint-denis-s-equipe-de-mini-cameras-.php> [accessed 27 May 2015]. ${ }^{40}$ Angélique Négroni, 'Les minicaméras se généralisent dans la police' (Le Figaro, 18 August 2014) <http://www.lefigaro.fr/actualitefrance/2014/08/17/01016-20140817ARTFIG00182-les-minicamerasse-generalisent-dans-la-police.php> [accessed 27 May 2015].

${ }^{41}$ Ibid.
}

The Internal Security Code ${ }^{42}$ stipulates that the recording and sharing of images obtained from the public domain can only be done by competent public authorities in a limited number of cases. These include the protection of buildings and public installations and their surroundings, prevention of attacks against persons and goods in places particularly exposed to risks of aggression, robbery or drug traffic, prevention of custom fraud and the prevention of terrorist acts. Body-worn cameras should also comply with the technical requirements imposed by the legislation to ensure the admissibility of video recording as legal evidence. ${ }^{43}$

The Code prohibits filming the interiors of residential buildings and their entrances. Recording of private premises should be authorised by the French Data Protection Authority.

The public should be informed in a clear and permanent way of the existence of the video surveillance system and of the authority or person in charge of the monitoring. This is particularly important to ensure the lawfulness of audio recording as the Penal Code forbids recordings without the previous knowledge or consent of all persons taking part in the communication.

\section{The role of body-worn cameras in police officers' accountability}

As shown in the previous section, police body-worn cameras are one additional tool at the disposal of law enforcement. They act as a transparency mechanism, subjecting to scrutiny that so far was limited to the parties to the interaction. Video surveillance is here targeted to specific events, places and people. Because it is mobile, it can happen everywhere, anytime. Its use is thus highly intrusive into the privacy of both citizens, who see their encounters with police documented, and police officers, who are being placed under (constant) monitoring during the performance of their task. It can also have an impact on other fundamental freedoms such as the freedom of movement as images are time-stamped, thus disclosing the location of a person at the moment of recording, or on the right to privacy of the home when recordings happen in private dwellings.

The monitoring of police behaviour through body-worn cameras thus raises a number of issues from a fundamental rights' perspective. The conditions of their deployment should be carefully assessed. As such, three main questions arise. (1) To what extent are the purposes for which they are deployed (evidence, deterrence of violent behaviour and overall improvement of the policing function) legitimate (Section 3.1)? (2) Are body-worn cameras the best means to achieve these goals (Section 3.2)? (3) How can their impact on privacy be limited through technical design (Section 3.3)?

\footnotetext{
${ }^{42}$ Code de la Sécurité Intérieure, art. L-251 and following.

${ }^{43}$ Ministerial Decree of 3 August 2007, "portant définition des normes techniques des systèmes de vidéosurveillance", NOR: IOCD0762353A <http://www.legifrance.gouv.fr/affichTexte .do? cidTexte=JORFTEXT000000649127>.
} 


\subsection{Improving the transparency of policing through police-worn cameras: a pressing social need?}

The use of police body-worn cameras creates two types of interference into privacy: one into police officers' right to privacy not to be monitored during their work hours, as any employee, and the other into citizens' right not to be filmed in public and private spaces.

The first interference, into police officers' privacy, can be justified by the need to protect citizens from a disproportionate use of force. The police enjoy extraordinary powers, mainly the one of exercising force in order to maintain public safety. Society thus holds a legitimate interest in requiring that the exercise of this power should be answerable, directly or indirectly. The primary purpose of accountability in that context is to avoid misuses of power. It is currently articulated amongst internal mechanisms (hierarchic controls) and democratic controls (checks and balances, judicial or parliamentarian reviews).

The second interference, into citizens' privacy, can be justified by the higher social need to ensure the accountability of police forces or the more specific need to protect police forces' physical integrity. The use of one justification or the other will however have an impact on the conditions of the implementation of body-worn cameras.

That being said, the integration of new elements and tools within the current system of accountability should be motivated by a genuine need to improve this system. As shown in the previous section, the motivation for equipping police officers with body-worn cameras relies on two main arguments. First is the increasing dissatisfaction with the service provided by the police to their communities, backed up by videos of citizens showing police misbehaviour. Second is the need to protect police officers from increasing violent interactions with the public. When there is evidence that either citizens or police are exposed to serious threats, the use for body-worn cameras would rely on sufficient grounds. Such is the US case, where the violence used by some police officers against citizens, sometimes leading to their death, is regularly reported by citizens. In Europe, the situation does not seem that serious, but sensitive social contexts can motivate the adoption of bodyworn cameras. The seriousness of the situation should anyway be assessed on a case-by-case basis.

\subsection{Suitability of body-worn cameras as an accountability tool}

When the need for reinforcing the accountability of police forces has been demonstrated, the suitability of body-worn cameras as accountability mechanism should be assessed. As accountability mechanism, they could act in two ways: to apportion responsibility and to encourage learning. Still, their use as a tool to provide reliable evidence, to reduce violent behaviour and improve policing calls for careful consideration.

\subsubsection{Body-worn cameras as a reliable source of evidence}

Body-worn cameras are first meant to be used as a backwardlooking mechanism, to apportion responsibility. Recordings are used to document encounters between the police and the public and to capture evidence. Reviews of recordings will help investigate and resolve complaints which involve officers, strengthen officers' accountability and enhance law enforcement agency transparency.

However, the ability to use the recording as source of evidence before courts is predicated upon their authenticity, reliability and admissibility. ${ }^{44}$ This will greatly depend on the technical features of the cameras. Over a dozen of models are currently available on the market, with heterogeneous feature sets. A 2012 report by the US Department of Justice synthesises variations with respect to key capabilities. ${ }^{45}$

First, the account given by the camera should be authentic. This means that it should be possible to positively tie evidentiary material to the incident. This is particularly important in that context as the images are expected to be used as "objective" truth. Technical considerations include the use of timestamps and features that affect the capacity of recording to accurately depict the crime scene such as camera placement, focal width and battery life.

Timestamps make it possible to prove the date and time of the incident. They are added to recordings by about half of the body camera models listed in a primer by the National Institute of Justice. ${ }^{46}$ This kind of metadata adds a temporal dimension to the recordings which could be tallied with external clues. Similarly, the integration of GPS data makes the evidence both more useful and more likely to be seen as admissible proof in court.

Camera placement possibilities have a significant impact since some of them ${ }^{47}$ replicate the officer's point of view, while others ${ }^{48}$ may record a different scene than the one the officer actually sees at a given moment. Such discrepancy weakens the correspondence between the recorded images and the officer's perception, and enables a wider margin of interpretation when examining the images. Some devices do not have a fixed mounting point and can therefore provide different vantage

\footnotetext{
${ }^{44}$ Fanny Coudert, Monica Gemo, Laurent Beslay, Fivos Andritsos, Fivos 'Pervasive Monitoring: Appreciating Surveillance Data as Evidence in Legal Proceeding', in 4th International Conference on Imaging for Crime Detection and Prevention (ICDP 2011), 1-6.

${ }^{45}$ U.S. Department of Justice, Office of Justice Programs, National Institute of Justice (NIJ). A Primer on Body-Worn Cameras for Law Enforcement, 2012, <https://www.justnet.org/pdf/00-Body-WornCameras-508.pdf>.

${ }^{46}$ Ibid.

${ }^{47}$ For instance head-mounted ones, with a clip above the ear (Op. Cit. fn. 35) or a clip on the helmet or hat (Sénat de Belgique, Annales $n^{\circ} 4$-116. Question orale de M. Philippe Monfils à la ministre de l'Intérieur sur «les priorités de la police en termes d'équipements», 2010, <http:// www.senate.be/www/? MIval=publications/viewPub\&COLL=H $\&$ PUID $=67111826 \&$ TID $=67116502 \& P O S=1 \&$ LANG $=$ fr $>$ ), or integrated with Google Glass devices (Yesenia Duran, 'Google Glass Finds its Way into Law Enforcement' (Law and Order, 1 April 2014) $<$ http://www.hendonpub.com/law_and_order/articles/2014/04/google _glass_finds_its_way_into_law_enforcement $>$ [accessed 28 May 2015] and Paul Marks, 'Body-worn cameras put police evidence beyond doubt' (New Scientist, 23 October 2013) <https://www.newscientist .com/article/mg22029404-400-body-worn-cameras-put-policeevidence-beyond-doubt/> [accessed 28 May 2015]).

${ }^{48}$ For instance, e.g. chest-mounted ones or ones clipped on clothes: 'Le Mans: Les policiers équipés de caméras portables' (Le Maine Libre, 6 June 2013) <http://www.lemainelibre.fr/actualite/le-mans-lespoliciers-equipes-de-cameras-portables-06-06-2013-60152> [accessed 27 May 2015].
} 
points depending on the decision of the officer using it. ${ }^{49}$ An additional consequence of camera placement is the stability of the video output, with head-mounted cameras normally yielding more stable images. High-end models may feature stabilisation mechanisms, but this implies higher costs.

The focal width offered by the models also varies, but most models provide a large angle of view and therefore record reasonably panoramic scenes. This means that irrelevant information might be recorded. Large angles of view do not encourage targeted recording. However, the angle of view of recording raises again the question of the discrepancies between the recorded images and what an officer can actually see, if the angle differs from the human field of vision.

Recommendations for this and other features have been defined by the Department of Homeland Security..$^{50}$ In particular, minimal requirements for battery life are defined. Too short battery life carries the risk of partial recording producing incomplete evidence. Video quality criteria such as resolution and frame rate are also mentioned. Again, such specifications have an impact on the value of the recorded evidence, with insufficient detail preventing an accurate representation of events.

These issues might however be mitigated thanks to an upcoming technology, image stitching. ${ }^{51}$ It makes it possible to combine the recordings of several different cameras to reconstruct a larger scenery. The presence of more than one police officer equipped with a body camera could hence provide richer information than the mere addition of the individual recordings through joint recording.

The latitude let to police officers to turn on and off the camera can also impact the authenticity of the recording. It may be tempting to recommend switching cameras on only in case of violence, but concerns have been voiced that the resulting recording will not contain the initial provocation against the police, and focus only on the police's violent reaction, thereby presenting a distorted image..$^{52}$ In Spain and in France, the cameras automatically record the previous 30 seconds to the moment when the police officer decided to start the recording. However, it is not clear yet whether such time span will be sufficient to provide an accurate account of the events.

Second, the recording should be reliable, i.e. nothing about how the evidence was collected and subsequently handled may cast doubts about its authenticity and veracity. Here, the way video is transferred from the devices to a centralised storage

\footnotetext{
${ }^{49}$ For instance, in the case of the cameras used by the LAPD, the devices can be easily clipped on to shirt lapels, hats or glasses (Michael Griffin, 'Privacy vs. Accountability: LAPD to Equip Officers with On-Body Cameras' (JETLaw, 21 January 2014) <http://www.jetlaw.org/2014/01/21/privacy-vs-accountability-lapdto-equip-officers-with-on-body-cameras/> [accessed 28 may 2015]. ${ }^{50}$ U.S. Department of Homeland Security, System Assessment and Validation for Emergency Responders Program (DHS SAVER). Wearable Camera Systems Assessment Report, 2011.

${ }^{51}$ Michael Adam, Christoph Jung, Stefan Roth, Guido Brunnett, 'Real-time Stereo-Image Stitching using GPU-based Belief Propagation', Vision Modeling and Visualization (VMV), 2009.

52 'Homme abattu dans les Marolles: le SLFP pas favorable aux bodycams' (RTBF.BE, 26 May 2013) <http://www.rtbf.be/info/societe/ detail_homme-abattu-dans-les-marolles-le-slfp-n-est-pas-favorableaux-bodycams?id=8003704>.
}

area is critical. In case officers perform uploads themselves and checks are not performed with sufficient rigor, censoring may occur during the chain of custody. Cameras with automated upload capabilities prevent this issue but provide less control over data flows. In any case, stored or transmitted data must be encrypted and digitally signed to ensure confidentiality and prevent tampering.

Finally, evidence is admissible if it conforms to legal rules concerning its gathering, conservation, communication and presentation. This includes both respect for the rules applicable to digital evidence preservation stemming from criminal law procedure and respect of rights of privacy of the persons recorded. This aspect will be dealt with in Section 3.3 with greater detail.

\subsubsection{Body-worn cameras as deterrent to violent behaviour} Body-worn cameras have the potential to act as powerful deterrent mechanism by exposing behaviour that was previously not scrutinised. Still, the latitude let to police officers to turn the camera on and off will be a decisive factor in that regard.

The one-year study conducted in Rialto shows that in order for body-worn cameras to be an efficient tool leading to sociallydesirable behaviour of the officers who wear them (and of citizens being videotaped), this should be accompanied by a given level of certainty of being apprehended in case of misbehaviour (self-awareness mechanism)..$^{53}$ The research departs from the hypothesis that CCTV cameras are weak behaviour modifiers, not because they failed as deterrent mechanism but rather because the risk to be apprehended is too low. If cameras are expected to influence behaviour and to serve as indicators that social norms or legal rules must be followed, then the level of awareness must be high. In that sense, Welsh and Farrington showed that the impact of CCTV cameras on crime, thus their ability to influence behaviour, was dependent on the degree of coverage of the area by the cameras, whether their use was combined with other interventions and if it was targeted to specific categories of crime. ${ }^{54}$

The author of Rialto's study purports that mobile cameras are likely to have a strong deterrent effect. The study showed what happens when the level of certainty of apprehension for professional misconduct was absolute. Police officers were equipped with body-worn cameras that captured all policepublic encounters. The results of the tests conducted in Rialto are appalling. ${ }^{55}$ Citizens' complaints were reduced in $88 \%$ and the use of force by police officer in $60 \%$.

This option might however face strong privacy obstacles, e.g. when the police officer enters private or sensitive areas (such as hospitals). It further subjects police officers to constant monitoring during their work, an extreme measure that can

\footnotetext{
53 Tony Farrar, 'Self-Awareness to Being Watched and SociallyDesirable Behavior: A Field Experiment on the Effect of BodyWorn Cameras on Police Use-of Force', March 2013, <http:// www.policefoundation.org/wp-content/uploads/2015/06/The-Effectof-Body-Worn-Cameras-on-Police-Use-of-Force.pdf $>$.

${ }^{54}$ Welsh and Farrington, Effects of Closed Circuit Television Surveillance on Crime, Campbell Systematic Reviews 2008:17, p. 19.

${ }^{55}$ Randall Stross, 'Wearing a Badge, and a Video Camera' (The NewYork Times, 6 April 2013) <http://www.nytimes.com/2013/04/07/ business/wearable-video-cameras-for-police-officers.html> [accessed 27 May 2015].
} 
only be justified under specific circumstances of greater risks for police officers or citizens. A trade-off must be found.

Striking the right balance between the expectation for cameras to act as self-awareness mechanism and their impact on privacy or to avoid chilling effects will certainly need further investigation. Indeed, it remains to be seen to what extent bodyworn cameras can act positively on police behaviour when police officers have the latitude to decide when to start and stop the recordings (under predefined guidelines). This for instance led ACLU to recommend that cameras should record systematically all interactions with the public, allowing officers to turn the camera off in other cases. ${ }^{56}$

\subsubsection{Body-worn cameras as a tool to improve police officers'} behaviour

Finally, body-worn cameras may allow acting upon the behaviour displayed by police officers during their encounters with citizens, thus improving it. Their deployment should be accompanied by organisational measures ensuring that police officers receive sufficient and meaningful feedback from their supervisors after incidents, eventually leading to sanctions.

In that sense, body-worn cameras can also act as forwardlooking mechanism, to encourage learning. Good behaviour is exemplified and internalised by police officers. Body-worn cameras could contribute to police officers' training and teach them how to behave in difficult encounters with the public. The US experience showed that body-worn cameras can serve as a teaching tool when supervisors review footage with officers and provide constructive feedback. Some law enforcement agencies used the recordings to highlight officers whose videos demonstrate exemplary performance by showing their footage at training programs or by showing the video during an awards ceremony. ${ }^{57}$ Yet, it should not be overlooked that the use of body-worn cameras also implies a change in the working conditions of police officers, as they become subject to potential greater scrutiny of their performance at work. ${ }^{58}$

With regard to the ultimate goal of body-worn cameras improving policing - the first results seem positive. The few studies performed by US police forces during trial tests seem to indicate that body-worn cameras have a positive impact on the relations between police and civilians. However, bodyworn cameras should not be approached as the magic bullet. Technology is no more than a means to achieve a goal. It cannot, by itself, build better relations between police and the general public, improve policing or solve inherent community problems. Body-worn cameras have as unique feature the potential to provide transparent records of events.

The question of the suitability of the use of police bodyworn cameras leads to a broader reflection on the circumstances under which the use of mobile cameras will bring added value

\footnotetext{
${ }^{56}$ American Civil Liberties Union (ACLU), Police Body-Mounted Cameras: With Right Policies in Place, a Win For All, 201, 2013, <https:// www.aclu.org/files/assets/police_body-mounted_cameras.pdf> [accessed 27 May 2015].

${ }^{57}$ US Department of Justice, Community Oriented Policing Services (COPS), Implementing a Body-Worn Camera Program, Recommendations and Lessons Learned 2014:26-27.

${ }^{58}$ Michael D. White, Police Officer Body-Worn Cameras: Assessing the Evidence, Washington, DC: Office of Community Oriented Policing Services, 2014.
}

to the function of policing and to the relations between police and the public. As a way of example, one commentator noted the importance of adequately understanding and addressing the social problems associated with, for instance, stop and search. ${ }^{59}$ Body-worn cameras should only be approached as one tool, part of larger efforts to improve policing practice. As for any technology, their introduction should be guided and properly framed in order to ensure wide and effective use. Systematic evaluations are required to learn about the context or the type of crime they can effectively address, and to adjust their use accordingly. ${ }^{60}$ In words of Custers and Begouw "using technology in policing is too complex to simply buy technological product off-the-shelf and start using them". Another illustration of the need to further study the impact of the use of bodyworn cameras concerns the effectiveness of the police services themselves. Indeed, it may be the case that, knowing that all their actions are recorded, police officers will tend to take as few risks as possible and interact less with citizens. This might cause a decrease in the quality of their work and thus of the level of protection enjoyed by citizens. The chilling effect that video surveillance has on observed individuals has been demonstrated elsewhere. ${ }^{61}$ Thus, as relatively untested technology, both the perceived benefits and concerns of police bodyworn cameras still need to be further researched and demonstrated. ${ }^{62}$

\subsection{Limiting the impact on fundamental rights: conditions of use and privacy by design (proportionality stricto sensu)}

The final aspect to be assessed is to what extent the impact of body-worn cameras on privacy can be limited by organisational and technical measures. We focus on four concerns: (1) the duty to inform filmed persons, (2) the time and content of the recordings, (3) the access to and storage of the recordings, and (4) additional risks from upcoming technologies.

\subsubsection{Duty to inform and consent}

One key principle applying to any personal data processing activity is to ensure its transparency. Under the data protection framework, when consent to be filmed is not required, the persons being filmed should at least receive adequate information about the fact that they are being filmed, the purpose of the recording and the person responsible for it.

It follows that the cameras should be made visible to the person being recorded. The recording of the time and the

\footnotetext{
59 Daniel Bear and Johannes Rieken, 'Those cheering for police body-worn cameras must think a little deeper' (The Guardian, 15 August 2014) <http://www.theguardian.com/commentisfree/2014/ aug/15/police-body-worn-cameras-liberal-democrats-proposalspolicies> [accessed 27 May 2015].

${ }^{60}$ Bart Custers, Bas Vergouw, 'Promising policing technologies: Experiences, obstacles and police needs regarding law enforcement technologies', Computer Law \& Security Review 2015;31:518-526. $<$ http://dx.doi.org/10.1016/j.clsr.2015.05.005>.

${ }^{61}$ See e.g. Giovani Butarelli, Report to the Council of Europe on "Protection of personal data with regard to surveillance and guiding principles for the protection of individuals with regard to the collection and processing of data by means of video surveillance", 2000.

${ }^{62}$ Michael D. White, 2014, op. cit fn 54.
} 
place of the data collection should also be made explicit. The fact that body-worn cameras are mobile makes it more difficult to meet these requirements. The monitoring is not focused on one predefined area and can be subject to the police officer's latitude. In addition, body-worn cameras are equipped with audio recording capabilities so as to give an account of the oral exchanges taking place. Spain has opted for featuring the cameras with yellow information labels. In France, police officers must, in addition, mention the recording orally.

Still, in some cases, a general duty to inform will not be sufficient and consent must be gathered before the recording takes place. This is particularly the case when police officers decide to film private dwellings, sensitive areas (such as hospitals), specific events or involve the collection of sensitive data (e.g. when the recording focuses on a crime victim).

\subsubsection{Time and content of the recording}

Constant recording does not seem an acceptable interference into the right to privacy of policemen and of the persons filmed. Question arise about how to set the limits of the recording so it is both efficient, i.e. likely to reach its goal, and not excessive.

The first consideration will be on the categories of individuals who could film and be filmed. Restrictions may apply on the officers wearing the cameras: for example, in some case their use was limited to armed officers. ${ }^{63}$ Restrictions may apply to the individuals being recorded, for example to suspects only. In some cases, only individuals about to get arrested or to get tickets could be filmed. ${ }^{64}$ Scenes involving victims raise additional questions: may victims be filmed at all? What of situations where both a suspect and a victim appear in the same scene? Considering that the protection of the victims should be the prime concern of police forces, does their increased vulnerability imply even greater privacy risks from filming?

Some technologies can help modulating who is being filmed. Automatic blurring or pixellation could obfuscate faces. ${ }^{65}$ Those masking techniques require the identification of critical image elements (i.e. subject faces) as a first step, using object detection techniques. Those elements can then be removed or obfuscated. However, a drawback of this approach is that

\footnotetext{
${ }^{63}$ Martin Naylor, 'Derbyshire police investigate "usefulness" of body cameras in wake of Mark Duggan inquest' (Derby Telegraph, 13 January 2014) <http://www.derbytelegraph.co.uk/Derbyshire-policeinvestigate-usefulness-body/story-20434996-detail/story.html> [accessed 27 May 2015]; 'Le Mans: Les policiers équipés de caméras portables' (Le Maine Libre, 6 June 2013) <http://www.lemainelibre fr/actualite/le-mans-les-policiers-equipes-de-cameras-portables06-06-2013-60152> [accessed 27 May 2015].

64 "When people get tickets or get arrested they're going to be taped" (JETLaw, 2014). See also in UK, the Police and Criminal Evidence Act (1984) defines the conditions under which a person may be photographed by a constable elsewhere than at a police station. ${ }^{65}$ Srinivas Gutta, Miroslav Trajkovic, Antonio J. Colmenarez, Vasanth Philomin. 'Method and Apparatus for Automatic Face Blurring'. Patent US 6959099 B2, 2005.
}

obfuscation is irreversible, i.e. it is not possible to recover the original images from the obfuscated version. ${ }^{66}$

The second consideration will bear on the circumstances of the recording. Should the recording be limited to specific events (public demonstrations, stop and searches, violent encounters) or should the police be allowed to use them during routine patrols? Should the recording be triggered automatically in certain cases, for instance when car sirens are turned on? Some contexts seem especially sensitive and may entail specific procedures. Some police departments systematically deactivate recording in hospitals. ${ }^{67}$ In the case of private homes, recording may be either completely forbidden, or require consent by inhabitants. ${ }^{68}$ For example, the Cheverly (Maryland, US) police department switches off recording in "private contexts," 69 although this notion is not explicitly defined and therefore includes a margin of appreciation by officers. In particular, it is not clear whether this applies to interactions between officers or to other situations as well.

Finally, the degree of freedom allowed to police officers for triggering recording must be defined clearly. Can body-worn cameras be turned off at all, or can only recording be switched on and off while the device is always functioning? In the latter case ${ }^{70}$ cameras cannot be turned off but are not constantly recording.

The question of when recording can be stopped by police officers is critical. ACLU argues that the recording must always be activated to prevent officers from editing on the fly to censor behaviour they do not want recorded. ${ }^{71}$ In Belgium, ${ }^{72}$ officers have full freedom to activate and deactivate recording. In some cases, procedures are defined: in the case of Laurel in the US, recording can be switched off but must be switched on every time an officer leaves a car to interact with individuals. ${ }^{73}$ Assuming officers are allowed at all to switch off recording, should they be able to do so during a single interaction with individuals? The risk of omitting embarrassing behaviour seems especially strong with this provision. For this reason, ACLU states that cameras should record "all interactions with the public". ${ }^{74}$ However, in some cases such as in Seine-SaintDenis (France), ${ }^{75}$ officers have full freedom to switch off recording at discretion.

\footnotetext{
${ }^{66}$ Information and Privacy Commissioner of Ontario, Privacy and Video Surveillance in Mass Transit Systems: A Special Investigation Report. Privacy Investigation Report MC07-68, 2008, <https://www.ipc.on.ca/ images/Findings/mc07-68-ttc_592396093750.pdf>.

${ }^{67}$ Rachel Weiner, 'Police body cameras spur privacy debate' (The Washington Post, 10 November 2013) <http://www.washingtonpost .com/local/crime/police-body-cameras-spur-privacy-debate/2013/ 11/10/7e9ee504-2549-11e3-b75d-5b7f66349852_story.html>.

${ }^{68}$ Ibid.

${ }^{69}$ Ibid.

${ }^{70}$ Information and Privacy Commissioner of Ontario, Op. Cit. fn 6257.

${ }^{71}$ American Civil Liberties Union (ACLU). Op. Cit. fn. 5651.

${ }^{72}$ Sénat de Belgique, Annales n 4-116. Question orale de M. Philippe Monfils à la ministre de l'Intérieur sur «les priorités de la police en termes d'équipements", 2010 <http://www.senate.be/www/?MIval $=$ publications/viewPub\&COLL=H\&PUID $=67111826 \&$ TID $=67116502$ $\& \mathrm{POS}=1 \& \mathrm{LANG}=\mathrm{fr}>$.

73 Rachel Weiner, 2013. Op.cit. fn 6358.

${ }^{74}$ American Civil Liberties Union (ACLU). Op. Cit. fn. 5651.

${ }^{75}$ Flore Galaud, Op. Cit. fn. 4035.
} 
Risks resulting from on-the-fly editing, in cases where officers are not subject to strict procedures with regards to recording, could be mitigated by tracking how often officers switch recording on and off and flagging those who do it exceptionally often. In this case, the privacy of officers is directly in tension with abuse mitigation.

\subsubsection{Access to and storage of recordings}

Assuming videos have been recorded, several questions remain open as to the circumstances under which they are stored, and who can access them and under which constraints.

Recordings can be either managed internally, or using the services of an external contractor. In both cases, procedures relative to video access, transmission and deletion must be defined, as well as the identities and roles of data controllers and processors. Since recordings will be centralised, privacy threats are especially significant during their storage: during this stage of the data life cycle, a large quantity of personal data is concentrated in a single spot. Video management conditions ought to be clarified accordingly.

A factor increasing privacy protection with regard to video management is the presence of accountability measures for access, generating histories of access, e.g. including the identity of the individual accessing the data, a timestamp and the purpose of access. This is of significant importance to avoid function creep, i.e. that footage is used for other purposes than the ones which motivated the initial recording. Another useful technology is on-the-fly (?) encryption of recordings, which increases confidentiality.

Even if access rights are defined, they must be technically enforced, and ACLU recommends ensuring the security of backoffice video data storage. ${ }^{76}$ The local or distributed nature of storage carries additional consequences. Some departments adopt cloud storage, ${ }^{77}$ it is not clear to which extent the cloud provider guarantees specific security measures (and the lack of such measures would represent a major source of risk). Backup procedures must be implemented, since the videos constitute evidence to be protected.

Indeed, one purpose or consequence of the recordings of body-worn cameras is to provide evidence. Should the videos only be reviewed in case of declared incidents or should supervisors display a more proactive behaviour by conducting randomised reviews? The latter increases pressure on officers by opening the door to sanctions even in the absence of misconduct allegations by the public.

The data retention period of the recordings should also be defined strictly. While a department in the US applies a retention limit as long as six months given the data are not tagged as evidence, ${ }^{78}$ there have been calls for a much shorter time, e.g. 30 days. ${ }^{79}$ Spain has opted for a stricter data retention period. Recording are deleted after a period of seven days if the recording is not required as evidence in a criminal investigation. In addition to this maximal retention time, another criterion is the conditions under which earlier deletion can

\footnotetext{
76 Ibid.

77 Rachel Weiner, 2013. Op.cit. fn 6358.

${ }^{78}$ Ibid.

${ }^{79}$ American Civil Liberties Union (ACLU). Op. Cit. fn. 5651.
}

occur, including the identities of agents who can perform deletions and the circumstances under which they can do so.

With regard to the right of access to the recordings, access by police officers, the individuals filmed and third parties will call for different rules. For example, one may wonder under what conditions police officers should be allowed to review their own recordings (and thus exercise their access right). In some cases, videos are centrally stored so officers can watch the videos originating from their own camera on their smartphones, but cannot edit nor delete them. ${ }^{80} \mathrm{~A}$ number of technologies relate to the security of existing videos rather than to the way the recording is done. Fine-grained access control to devices could restrict playback to the officer to whom the device was assigned, in cases where playback is at all available on the body camera. In one use case in the US, officers can only see their own footage, not the ones from their peers, but a supervisor has access to all videos. ${ }^{81}$

In addition to access by police officers, the conditions to grant access to individuals appearing in recordings must be clearly defined. From a data protection point of view, citizens have a right to access the recording in which they appear, which should be balanced against the right to privacy of other persons appearing on the footage. This balance is usually made by blurring the faces of the other persons involved. Other issues stem from the fact that the recordings are meant to be produced as evidence in criminal proceedings. The question here is whether the access by data subjects should be limited to their representatives (lawyers) or if they should be granted a direct access to the footage. For instance ACLU supports an effective application of the right of access, which should not be restricted to lawyers in the context of a criminal procedure. ${ }^{82}$ Finally, the requests of third parties requesting access under the Freedom of Information Act, wherever such possibility is regulated by the legal framework, will call for a balancing between the right to information and the right to privacy of the persons appearing on the footage.

\subsubsection{Risks posed by upcoming technologies}

A number of video camera technologies, existing or currently under development, have a significant impact on privacy and should therefore be taken into account when assessing the impact of wearable body-worn cameras. A recent European project (SurPRISE) highlighted many such features. ${ }^{83}$ Some technologies make it possible to isolate the position or movement of recorded entities. Faces may be matched against databases or recognised. The advent of behavioural pattern recognition techniques raises the question of whether (or when) these techniques could be used to identify individuals even when their faces are not recorded in detail. Even more intrusive

\footnotetext{
${ }^{80}$ Rachel Weiner, 2013. Op.cit. fn 6358.

${ }^{81}$ Ibid.

${ }^{82}$ Ibid.

${ }^{83}$ SURPRISE. D 3.1 - Report on surveillance technology and privacy enhancing design, 2013 <http://surprise-project.eu/wp-content/ uploads/2013/06/SurPRISE-D3.1-Report-on-surveillance-technologyand-privacy-enhancing-design.pdf>.
} 
mechanisms such as automated emotion recognition and classification are under development. ${ }^{84}$

The capture of additional metadata, for instance geographical location through GPS, enriches the resulting recording and can be seen as an additional privacy threat. Thermal imaging has also been proposed in the context of surveillance, and can be used to track individuals in low lighting conditions. ${ }^{85}$ Thermal facial pattern recognition has been proposed in the context of biometric identification, ${ }^{86}$ but one could envision its use in more adversarial contexts involving police officers and suspects. If these techniques become commonly available in commercial body-worn cameras, the systematic tracking and automatic identification of individuals appearing in recordings of policepublic interactions cannot be discarded.

Body-worn cameras are normally assumed to record images statically, but remote control from a command centre could be combined with pan-tilt-zoom capabilities to selectively record operator-chosen areas picked from a scene. Face recognition might also be combined with pan-tilt-zoom to achieve similar effects without the need for remote control. In both cases, the produced video is less neutral and the link to the officer's field of vision is less straightforward, complicating any discussion involving the question of what visual information exactly was available to the involved officer.

\section{Recommendations: body-worn cameras for the police and beyond}

In the previous sections, we have presented an assessment of the current situation in the usage of police body-worn cameras for law enforcement from the experimental, technical and legal points of view. As discussed in Section 2, different countries are at varying stages of level of adoption of this technology but it is spreading across the world, to the point that we may imagine that most countries will adopt it sooner or later (even if adoption may occur at different scales and in different conditions). Indeed, motivations for the adoption of police bodyworn cameras are similar in all countries:

1. For civil society, the need to make police more accountable.

2. For police officers, the need to protect themselves against false accusations.

3. For policy-makers and society, the expected pacifying effect on the interactions between police and citizens.

In addition, even if some criticisms have been voiced, the predominant view of the stakeholders seems to be that in most

\footnotetext{
${ }^{84}$ Yisu Zhao, Xin Wang, Miriam Goubran, Thomas Whalen and Emil M. Petriu, 'Human emotion and cognition recognition from body language of the head using soft computing techniques', Journal of Ambient Intelligence and Humanized Computing, Springer, 2013.

${ }^{85}$ Wai Kit Wong, Poi Ngee Tan, Chu Kiong Loo and Way Soong Lim. 'An Effective Surveillance System Using Thermal Camera', International Conference on Signal Acquisition and Processing (ICSAP), 2009.

${ }^{86}$ Siu-Yeung Cho, Chan Wai Ting and Chai Quek, 'Thermal Facial Pattern Recognition for Personal Verification Using Fuzzy CMAC Model', International Journal of Innovative Computing, Information and Control, 2011.
}

of the contexts in which they have been used so far the benefitrisk ratio of police body-cameras is quite positive. Some experimental results, such as the $88 \%$ reduction in citizen complaints and $60 \%$ reduction in uses of force in Rialto, are quite impressive - even though they need to be confirmed at a larger scale.

The situation is not that clear on the legal side however, and most countries are still trying to figure out how to adapt their legislation to frame the use of bodycams by the police. In this section, we present our analysis of the benefits and risks of the deployment of police body-worn cameras and distinguish between short-term recommendations and a longer term reflection about the potential generalisation of the approach.

\subsection{Benefits of a cautious deployment of police body- worn cameras}

A possible line of reasoning in this matter is a comparative analysis with traditional video-surveillance cameras, which is the closest existing technology. Technically speaking, the main differences between the two instruments are the following:

1. Body-worn cameras are not necessarily (even not usually) switched on permanently: they may be under the control (partial or total) of the police officers wearing them. Officers may be able to decide to turn them on or off, or even to delete footage.

2. Body-worn cameras can simultaneously record audio and video and capture close-up images that allow for the use of facial recognition technology.

3. Body-worn cameras are mobile and can potentially be used everywhere, including in places which are out of reach of traditional video-surveillance cameras, such as homes or hospitals.

If appropriate measures are taken, we believe that all these features can be turned into advantages of bodycams (with respect to privacy protection) in comparison with fixed videosurveillance cameras. Because they are mobile and possibly turned on by police forces, body-worn cameras do not record individuals indifferently and permanently: they can rather be used in specific places and at specific times where and when a significant event occurs. In addition, if police officers wear a clear sign (or ask people for their consent, which might not be easy in practice), the risk of being filmed without noticing it (which has become the norm in most modern cities) is much lower. If misused, their ability to record sounds as well as images can not only obviously become an additional intrusion capacity but they can also improve the quality and the richness of the recording and therefore reduce the risk of misinterpretation.

However, it is necessary to ensure that these benefits are not outweighed by new privacy threats. Appropriate guarantees can be provided by a combination of technical, organisational and legal measures. For example, it is of prime importance that:

1. Police officers have clear instructions regarding camera operation (for example to ensure that any encounter with the public would be covered, except in situations where the consent of the people involved is required and not granted, 
with appropriate evidence of such refusal ${ }^{87}$ ) and incur sanctions in case of breach of these instructions. For these sanctions to be really deterrent, they must be severe enough and associated with actual checks of the records. In addition, if a police officer is accused of misconduct for any event which is not recorded and for which (s)he cannot justify the lack of record, this should "create an evidentiary presumption against the officer" (ACLU 2013) and be considered an aggravating factor.

2. Cameras record a sufficient period of time ${ }^{88}$ preceding the button-pressing by the police officer to ensure that any relevant event preceding the triggering is recorded. Indeed, experience shows that such events can be useful to fully understand the context.

3. Police officers wear clear sign showing that they use cameras, and obtain the consent of the people involved in certain situations such as in private dwellings. They must also keep track of such consent or refusal.

4. Police officers cannot delete, edit or otherwise modify any record.

5. The records are audited by dedicated police supervisors on a regular basis to ensure the deterrence effect: as discussed in Section 3.2, knowing that their actions are recorded may have little effect on police officers if they also know that the records are deleted without ever being watched.

6. The records are stored in a secure way for a well-defined period $^{89}$ and then automatically (and securely) deleted. In addition, it is essential that precise access control rules are defined and implemented and all accesses to the records are auditable. Only accredited policy officers, justice officers and individuals appearing in recordings should be allowed to see footage, and only in specific conditions. The records should never be released publicly without the consent of the persons involved.

7. No face recognition feature is integrated in the system during or after the collection of data, since it is not necessary for the purpose and could divert the system from its official objective. Function creep should be avoided by all means since it would ruin the very purpose of such systems: to enhance trust.

These conditions are in line with the recommendations of ACLU (ACLU 2013), which include additional suggestions about flagging videos and securing the back-end system. They are not meant to be exhaustive, but we believe that they already provide sufficient safeguards to ensure that the benefits of police bodycams in terms of accountability (and deterrence against police abuse) outweigh the risks in terms of privacy.

To conclude this section, one caveat must be added however. The use of police bodycams should not lead to complacency or over-reliance on technology. Police bodycams are sometimes

\footnotetext{
${ }^{87}$ Another option would be to require to turn turning the camera on only for specific missions such as security order.

${ }^{88}$ The precise amount of time is to be assessed by field experts. This requirement means that cameras are in fact permanently recording but deleting their records after this one minute period unless the police officer has pressed on the button.

${ }^{89}$ As suggested by ACLU (Op. Cit. fn. 5651.), "retention periods should be measured in weeks, not years".
}

presented as the ultimate solution to ascertain a sequence of events in case of disagreement about the behaviour of police forces. As discussed in Section 3, even if police bodycams can of course contribute a lot to establish the truth (and they are used precisely for this reason), one must keep in mind that they can only provide pictures taken from a particular position, with a specific coverage angle and within a limited period of time. In addition, the quality of the pictures and the sound themselves may not be perfect. As a consequence, one should not rely on police bodycams to be the absolute and unique source of evidence for any event involving police forces, even though they can greatly contribute to establish the truth.

\subsection{Beyond police: where to draw the line?}

Beyond their use by police forces, bodycams raise challenging questions in terms of accountability, privacy and even at a political level - about the type of society in which we would like to live in. Indeed, if we conclude as we did in the previous subsection, with a favourable (even if cautious) position about the use of bodycams by the police, the next question could be the following. If their use by the police is legitimate, or even desirable, what about other professions such as prison officers, custom officers, bailiffs, transport ticket controllers and so on? Indeed, all these professionals may also be caught up in situations of conflict with the public that might escalate into violence. Different positions could then be taken, depending on the acceptable grounds put forward for the use of the bodycams. The discussion in Section 3 shows that three main purposes are put forward for their use:

1. The need for more accountable police forces, and to protect citizens from police abuse.

2. The need for police officers to protect themselves from false and malevolent accusations.

3. The need for society to ensure peaceful relations between police and citizens and to minimise public unrest.

Considering the first and third purposes only would lead to accept or even to recommend the use of bodycams by any professional with the power of inflicting harm to people. This would obviously include any professional carrying weapons. But what about professions which could involve risks to the public, even risks of death, such as bus drivers or surgeons? The main difference in this case is that harms would be unintentional, but it could still result from professional misconduct or negligence. If the objective is to protect citizens and enhance the accountability of professionals who are in a position to harm them, why not consider also bodycams in such activities?

The second objective would lead to even larger acceptance of bodycams. Indeed, professionals who can be subject of malevolent accusations are numerous. The first example concerns teachers, professors, nurses and all activities in contact with children in which false accusations of child abuse have been reported. One could also consider civil servants in public administration services, or potentially any professional in contact with the public who can be wrongly accused by dissatisfied customers. Obviously, the potential damage suffered by professionals can vary a lot (from criminal sanctions to disciplinary sanctions and emotional distress), but the 
question is again: where to draw the line? On which basis can we decide that the risk of false accusation for a professional is high enough to justify the use of bodycams (or simple cameras when their work is sedentary) to protect them, or insufficient to put the privacy of the public at risk?

In fact, the slope is even more slippery with the selfprotection justification because it could be potentially valid for any person, in any activity involving an interaction with another individual. Indeed, if teachers are allowed (on a voluntary basis) to wear bodycams to protect themselves, why should their pupils not be able to do so? If a person is filmed by a civil servant in a city hall or by a salesman in a shop, why should not he be allowed to film them? Actually, as discussed in Section 3 , this is precisely the argument used by some police officers to claim the use of bodycams. Following this argument, anyone could be entitled to wear cameras because anyone could one day be the victim of false accusations and would like to be in a position to prove his good faith. This argument is not as futurist as it may seem since it is already used by one million Russian drivers using dashboard cameras to be able to defend themselves against fraudulent insurance claims in case of accidents. ${ }^{90}$

The next step in this line of thoughts is the "lifelogging" attitude. Again, some technophiles have already taken this path. For example, Gordon Bell wrote in Total Recall:"1 "Imagine how it could affect therapy sessions, friendly wagers, court testimony, lovers' spats (. . .). Imagine how easy it will be to prove that repairs were done, that a salesman went back on his word, or that the dog really did eat your homework. Think of how nice it would be to have recordings of childhood conversations with your best friend, or a complete audio library of the millions of priceless things your kids said." For the last years, Bell has recorded all what he said, what he has seen, his movements, so basically all his activities. He also wears a camera taking pictures of what he sees every thirty seconds.

Needless to say, the generalised use of bodycams, which naturally leads to the idea of life-logging, would have a tremendous impact on social life for various reasons. Actually, one could say that the two objectives sought with police bodycams would be magnified to the extent that their consequences are incalculable:

1. Everyone $\mathrm{e}^{92}$ would become accountable and should be able to produce evidence in case of accusation. This means that people reluctant to the use of bodycams would actually have to use them or to risk of suffering evidentiary presumption against them in case of accusation.

2. Behaviour of individuals itself would transform because of the observer effect, and even more markedly if they know that the records could possibly be shown as evidence.

The result of this trend would be what has been called a sousveillance society, ${ }^{93}$ or the surveillance of everyone by everyone, with obvious risks of paternalism, conformism and uniformity of behaviour.

Obviously, the adoption of police bodycams does not inevitably lead to this extreme scenario; but there are sufficient preliminary signs that this path could actually be followed by our technophile societies. The development of Google Glass, even though its primary objective is not surveillance, could be another small step in this direction by accustoming people to see cameras everywhere. Therefore, we believe that the deployment of police bodycams should be accompanied by a continuous assessment of its consequences (with respect to all the objectives discussed above) and a longer-term reflection about the generalisation of body-worn cameras and their impact on society.

\section{Acknowledgements}

This paper was made possible thanks to the funding of the PARIS project (PrivAcy pReserving Infrastructure for Surveillance), European Union Seventh Framework Programme, under Grant Agreement No: 312504 and the German Research Foundation (DFG) under Grant Agreement No. BU 630/28-1.

\footnotetext{
${ }^{90}$ Wikipedia, Dashcam <https://en.wikipedia.org/wiki/Dashcam>.

${ }^{91}$ Gordon Bell and Jim Gemmell, 'Total Recall: How the E-Memory Revolution Will Change Everything', Dutton Adult, 2009.
}

\footnotetext{
92 or almost, considering that the refusal to adopt the technology would in itself become suspicious, its use would become the norm.

${ }_{93}$ Wikipedia, Sousveillance <https://en.wikipedia.org/wiki/ Sousveillance>.
} 